\title{
Detailed landfill leachate plume mapping using 2D and 3D Electrical Resistivity Tomography- with correlation to ionic strength measured in screens
}

\author{
P.K. Maurya*1 , V.K. Rønde ${ }^{2}$, G. Fiandaca ${ }^{1}$, N. Balbarini' ${ }^{2}$,E. Auken ${ }^{1}$, P.L. Bjerg ${ }^{2}$, A.V. Christiansen ${ }^{1}$ \\ ${ }^{1}$ Aarhus University, Institute of Geoscience C.F. Møllers Alle 4, 8000 Aarhus C, Denmark. \\ ${ }^{2}$ Technical University of Denmark, Department of Environmental Engineering, Technical University \\ of Denmark, Bygningstorvet, building 115, 2800 Kgs. Lyngby, Denmark
}

Published in

Journal of Applied Geophysics

DOI

http://dx.doi.org/10.1016/i.jappgeo.2017.01.019

Publication date

January 2017

Document Version

Peer reviewed version

Citation (APA):

Maurya, P. K., V. K. Rønde, G. Fiandaca, N. Balbarini, E. Auken, P. L. Bjerg, and A. V. Christiansen, 2017, Detailed landfill leachate plume mapping using 2D and 3D Electrical Resistivity Tomography - with correlation to ionic strength measured in screens: Journal of Applied Geophysics, v. 138, p. 1-8. 


\section{Accepted Manuscript}

Detailed landfill leachate plume mapping using 2D and 3D Electrical Resistivity Tomography - with correlation to ionic strength measured in screens

P.K. Maurya, V.K. Rønde, G. Fiandaca, N. Balbarini, E. Auken, P.L. Bjerg, A.V. Christiansen

PII:

S0926-9851(17)30057-5

DOI: $\quad$ doi:10.1016/j.jappgeo.2017.01.019

Reference: $\quad$ APPGEO 3189

To appear in: $\quad$ Journal of Applied Geophysics

Received date: 28 August 2016

Revised date: $\quad 16$ December 2016

Accepted date: 14 January 2017

Please cite this article as: Maurya, P.K., Rønde, V.K., Fiandaca, G., Balbarini, N., Auken, E., Bjerg, P.L., Christiansen, A.V., Detailed landfill leachate plume mapping using 2D and 3D Electrical Resistivity Tomography - with correlation to ionic strength measured in screens, Journal of Applied Geophysics (2017), doi:10.1016/j.jappgeo.2017.01.019

This is a PDF file of an unedited manuscript that has been accepted for publication. As a service to our customers we are providing this early version of the manuscript. The manuscript will undergo copyediting, typesetting, and review of the resulting proof before it is published in its final form. Please note that during the production process errors may be discovered which could affect the content, and all legal disclaimers that apply to the journal pertain. 


\title{
Detailed landfill leachate plume mapping using 2D and 3D Electrical Resistivity Tomography - with correlation to ionic strength measured in screens
}

\author{
P.K. Maurya* ${ }^{1}$, V.K. Rønde ${ }^{2}$, G. Fiandaca ${ }^{1}$, N. Balbarini ${ }^{2}$,E. Auken ${ }^{1}$, P.L. Bjerg ${ }^{2}$, A.V. Christiansen ${ }^{1}$
}

*Corresponding author, Pradip.maurya@geo.au.dk,

${ }^{1}$ Aarhus University, Institute of Geoscience C.F. Møllers Alle 4, 8000 Aarhus C, Denmark.

${ }^{2}$ Technical University of Denmark, Department of Environmental Engineering, Technical University of Denmark, Bygningstorvet, building 115, 2800 Kgs. Lyngby, Denmark

Submitted for Journal of Applied Geophysics August 2016 


\section{Abstract}

Leaching of organic and inorganic contamination from landfills is a serious environmental problem as surface water and aquifers are affected. In order to assess these risks and investigate the migration of leachate from the landfill, 2D and large scale 3D Electrical resistivity tomography were used at a heavily contaminated landfill in Grindsted, Denmark. The inverted 2D profiles describe both the variations along the groundwater flow as well as the plume extension across the flow directions. The 3D inversion model shows the variability in the low resistivity anomaly pattern corresponding to differences in the ionic strength of the landfill leachate. Chemical data from boreholes agree well with the observations indicating a leachate plume which gradually sinks and increases in size while migrating from the landfill in the groundwater flow direction. Overall results show that the resistivity method has been very successful in delineating the landfill leachate plume and that good correlation exists between the resistivity model and leachate ionic strength.

Keywords: Large scale 3D ERT, Landfill, Leachate plume, lonic strength, Hydrogeophysics 


\section{Introduction}

Groundwater contamination is one of the most serious environmental risks, especially in and around areas with an industrial history. The sources of contaminations are either called point source contamination or areal contamination. Point source contaminations include landfills, industrial waste disposal sites, accidental spills, leaking gasoline storage tanks, etc. Areal contaminations are for instance the chemicals used in agriculture such as fertilizers and pesticides. Among the point source contaminations, landfills with various types of solid waste are quite common and can potentially generate contaminated leachate plumes (Barker et al., 1986; Baxter, 1985; Bjerg et al., 1999;

Christensen et al., 2001; Cozzarelli et al., 2011). Over time some of the landfill waste materials degrade and dissolve, and as water perches through landfill leachate with inorganic and organic constituents are generated. Often the older landfills do not have a leachate collection or liners beneath the landfill which may result in leachate contaminating groundwater down-gradient from the landfill.

The migration of a leachate plume can potentially contaminate aquifers and surface waters for decades and thus poses a long term serious risk to the health and environment (Bjerg et al., 2014; Bjerg et al., 1999). To evaluate these risks, an understanding of the interaction between the surrounding aquifers and the contaminant plume leaching from the landfill is becoming increasingly pertinent. Hence, a main target in field investigations of landfills is mapping and characterizing the contaminant plume. The most common techniques used for this purpose include geological and hydrogeological characterization of aquifer properties by use of borehole information, as well as chemical analyses of soil and water samples. However, these techniques provide limited spatial 
information, which might lead to incomplete site investigation and inadequate remedial designs. Geophysical measurements minimize this spatial information gap as they can provide extensive lateral coverage with high-resolution information.

Non-invasive geophysical methods have been used extensively to investigate the composition and structure of the subsurface, and in particular electrical resistivity tomography (ERT) has been used for studying the landfills and related contaminated sites (Casado et al., 2015; Konstantaki et al., 2015; Slater and Binley, 2006; Vargemezis et al., 2015; Wang et al., 2015). The application of ERT for the study of the landfill sites addresses two main complimentary issues: (1) Mapping of extent of landfill sources (Bernstone et al., 2000; Ogilvy et al., 2002); and (2) Identification and mapping of landfill leachate plumes (Acworth and Jorstad, 2006; Perozzi and Holliger, 2008; Zume et al., 2006). Hence, surface ERT methods can be used for characterising the landfill and leachate migration, in case of an increased ion concentration in the groundwater. In this paper, we will study a landfill with a detailed site characterization and plume monitoring and show that combined use of 2D and large-scale 3D ERT data enables detailed imaging of a heterogeneous flow pattern of a contaminated groundwater leachate. The 3D layout contains a very large number of electrodes, which enables a hitherto unseen spatial coverage while maintaining a high resolution.

Inorganic constituents such as chloride, hydrogen carbonate, ammonium, and potassium are often present in landfill leachate contaminated groundwater (Christensen et al., 2001). This causes an increase in the electrical conductivity $(E C)$ of the contaminated groundwater resulting in a resistivity contrast between the contaminated zone and the host aquifer, which makes it detectable by surface resistivity surveys. Multichannel measurements (Dahlin and Zhou, 2006) have made the ERT method 
robust, faster and more convenient to perform in the field. 2D inversion codes (Auken et al., 2014a; Loke and Barker, 1996b) are available and can produce high resolution subsurface resistivity images. However, in the case of three-dimensional (3D) resistivity structures, such as a landfill leachate plume, 2D resistivity methods may be insufficient, which then calls for 3D resistivity techniques both for data acquisition as well as data processing and inversion.

Three dimensional (3D) measurements are generally carried out by deploying the electrodes in parallel lines or by using a regular grid. Though, many instruments can handle only a limited number of electrodes (typically 64-128), which limits the areal coverage that can be obtained (Dahlin et al., 2002). For larger coverage, more electrodes are needed which puts demands on the switching capabilities of the system. A flexible and expandable 3D acquisition system using a set of parallel cables in a fish-bone structure was presented by Auken et al., (2014b). Here, we will apply a further developed version of this system to a landfill leachate plume for the first time.

3D modelling and inversion of resistivity data is generally based on finite difference (Loke and Barker, 1996a; Park and Van, 1991; Zhang et al., 1995) and finite element methods (Sasaki, 1994; Yi et al., 2001). Most of these algorithms are based on Gauss-Newton techniques for optimization and do not consider the surface topography. (Günther et al., 2006) have presented an algorithm based on unstructured tetrahedral meshes and finite element forward calculation. The algorithm also incorporates the surface topography and can be applied to large scale 3D problems as encountered in practice. 
In the present study we use and demonstrate an extended and improved version of the flexible and expandable 3D system (Auken et al., 2014b) in combination with the inversion algorithm by Günther et al. (2006). The aim of the study is to delineate and describe the leachate plume migrating from a landfill and compare with field observations of water quality in the landfill leachate plume.

The measurements were carried out at a Grindsted landfill site in the southern part of Jutland, Denmark (Kjeldsen et al., 1998a; Bjerg et al., 1995). The landfill was pre-investigated by 2D ERT profiles and 2D resistivity models were also used to compare with the inorganic water chemistry obtained from water sampling of boreholes in the landfill leachate plume.

\section{Study area and background description}

\subsection{Grindsted Landfill}

The Grindsted landfill site is located on top of a flat glacial outwash plain (Figure 1; Heron et al., 1998). Between 1930 and 1977 approximately 300,000 tons of waste was deposited over an area of 10 ha, most of it between 1960 and 1970 (Kjeldsen et al., 1998b). There is no leachate collection or liner beneath the landfill. The deposited waste consists of municipal solid waste, industrial waste, sewage treatment waste, and demolition waste. The landfill source has been subject to a number of investigations (Kjeldsen et al., 1998b), which suggest that there is a pronounced spatial variability in the leachate and that the landfill can be divided into strong and medium leachate zones (Figure 1). The concentration of chloride, ammonium, and dissolved organic carbon (DOC) in the strongest leachate zones is typically 20-40 times higher than in the weak leachate zones. The waste in the northern part originates from a local pharmaceutical factory site, which deposited liquid industrial 
waste in a lagoon. The waste had very high ion content and chemical waste residues including pharmaceutical compounds. The waste in the southern part is mainly demolition waste, while the remaining part of the landfill hosts municipal household waste, demolition waste and smaller amounts of chemical waste. The described differences in waste composition are clearly reflected in EC values for water samples collected in in the groundwater just below the landfill (Table 1).

Table 1: EC (columns 2-4); lonic strength, $\mu$ (columns 5-7), and, of leachate types representing the four areas shown on Figure 1. Ionic strength is calculated from water chemistry measurement reported in Kjeldsen et al. (1998a).

\begin{tabular}{|c|c|c|c|c|c|c|}
\hline Leachate Type & $\begin{array}{c}\text { Min EC } \\
(\mathrm{mS} / \mathrm{m})\end{array}$ & $\begin{array}{c}\text { Max EC } \\
(\mathrm{mS} / \mathrm{m})\end{array}$ & $\begin{array}{c}\text { Average EC } \\
(\mathrm{mS} / \mathrm{m})\end{array}$ & $\begin{array}{c}\text { Min } \mu \\
(\mathrm{meq} / \mathrm{L})\end{array}$ & $\begin{array}{c}\text { Max } \mu \\
(\mathrm{meq} / \mathrm{L})\end{array}$ & $\begin{array}{c}\text { Average } \mu \\
(\mathrm{meq} / \mathrm{L})\end{array}$ \\
\hline Strong & 752 & 2177 & 999 & 23.5 & 376.8 & 116 \\
\hline Medium North & 294 & 650 & 472 & 20.9 & 55.1 & 37 \\
\hline Medium South & 285 & 391 & 324 & 7.4 & 37.9 & 26 \\
\hline Weak & 92 & 432 & 199 & .3 & 50.2 & 12 \\
\hline
\end{tabular}

\subsection{Geology and Hydrogeology}

The geology of the area consists primarily of sand where the upper 10-12 m are divided into Quaternary and Tertiary sand layers separated by discontinuous silt and sand layers (Heron et al., 1998). Below is a $1 \mathrm{~m}$ clay layer underlain by a more regional micaceous sand layer, which is approximately $65 \mathrm{~m}$ thick and confined by a low permeable clay layer at a depth of approximately 80 $m$. Three thin lignite layers are present in the micaceous sand unit. 


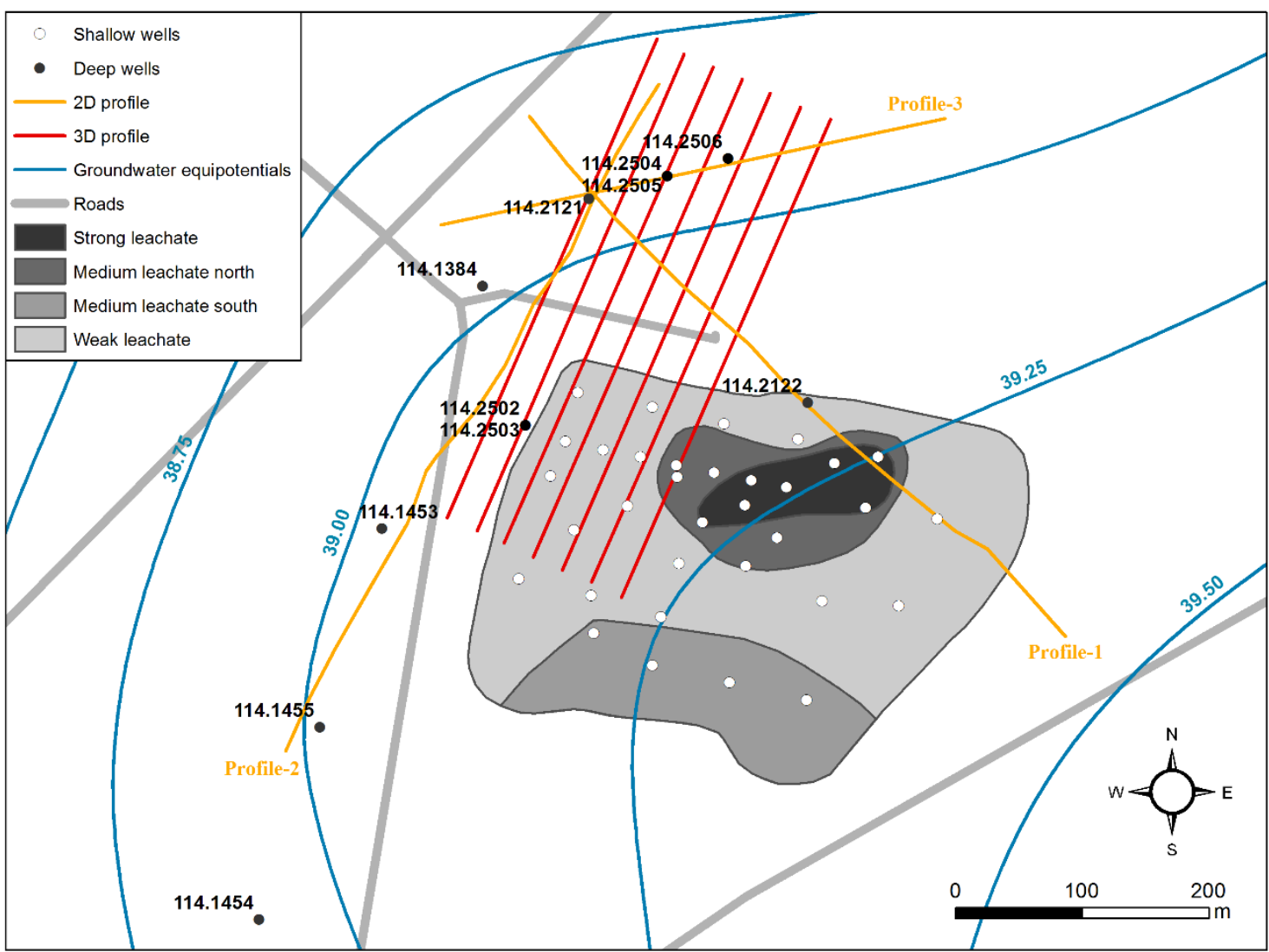

Figure 1 Map of Grindsted Landfill, groundwater flow field, placement of boreholes and geophysical measurements. Groundwater iso-potential lines are shown as blue curves, while corresponding hydraulic heads are given in meters. Geophysical profiles for the 3D ERT survey are shown by red parallel lines and orange lines are the 2D ERT profiles. The source strength of the landfill leachate contaminated groundwater is indicated inside the landfill body (based on data from Kjeldsen et al., 1998a).

Investigations of hydraulic conductivity and hydraulic gradient show that an average linear groundwater flow velocity is $50 \mathrm{~m}$ per year for the glaciofluvial sand $(0-6 \mathrm{~m})$ and $10 \mathrm{~m}$ per year for the upper Tertiary sands (8-12 m below surface) (Albrechtsen et al., 1999; Bjerg et al., 1995; Lonborg et al., 2006; Rugge et al., 1999). The lower parts of the Tertiary deposits have presumably higher flow velocities, but the data is scarce (Barlebo et al., 1998). The groundwater iso-potential map (Figure 1) based on data from (Orbicon, 2013) suggests that the overall groundwater flow is north-westerly and 
that the flow has a diverging pattern indicated by a semi-circular iso-potential line. The flow field shows some temporal variation, which can enhance spreading of contamination (Kjeldsen et al., 1998b).

\section{System setup and data acquisition}

Before setting up the 3D system we investigated the area using three 2D profiles as shown in Figure 1. These data were collected using a four-cable setup with roll-along(Dahlin and Zhou, 2006). A gradient array type of protocol was used. Profile 1 and 2 are $600 \mathrm{~m}$ long each and profile 3 is $400 \mathrm{~m}$ long. Total 1800 quadrupoles were collected for long profiles and 691 quadrupoles were collected for short profile

The 3D ERT system used for this study was originally designed for a monitoring study (Auken et al., 2014b), which consisted a 64 channel Syscal resistivity meter, field PC and six switch boxes developed in-house. The original system has been modified and migrated to an ABEM LS terrameter (www.abem.se). The whole system was powered by an uninterrupted power supply (UPS) consisting of a gasoline powered AC generator, three 120 Ah $12 \mathrm{~V}$ car batteries and a power management control unit. The control system always charged one battery and used the other for acquisition. Batteries were swapped automatically by the control unit.

Figure 2 shows the various components of the 3D system where seven parallel lines (63 electrodes in each) are handled by six switch boxes. Each line consisted of four cables where $5 \mathrm{~m}$ electrode spacing was used for the two inner cables(21 electrodes in each where one electrode was shared between 
two cable) and $10 \mathrm{~m}$ spacing was used for the two outer cables(11 electrodes in each), making each line $410 \mathrm{~m}$ long. Profiles were seperated $25 \mathrm{~m}$ apart hence making total coverage $410 \mathrm{~m}$ by $150 \mathrm{~m}$. Switch boxes were connected in the middle of the profiles and controlled by a PC which enables automatic selection of desired combinations of cables for data acquisition. The array of measurements (protocols) for each four cable combination was preloaded in the LS Terrameter and executed sequentially by the PC.

The switch boxes can connect their own line to the resistivity meter or pass the instruction through to the next switch box. This enables flexibility to realize three types of measurements as given below.

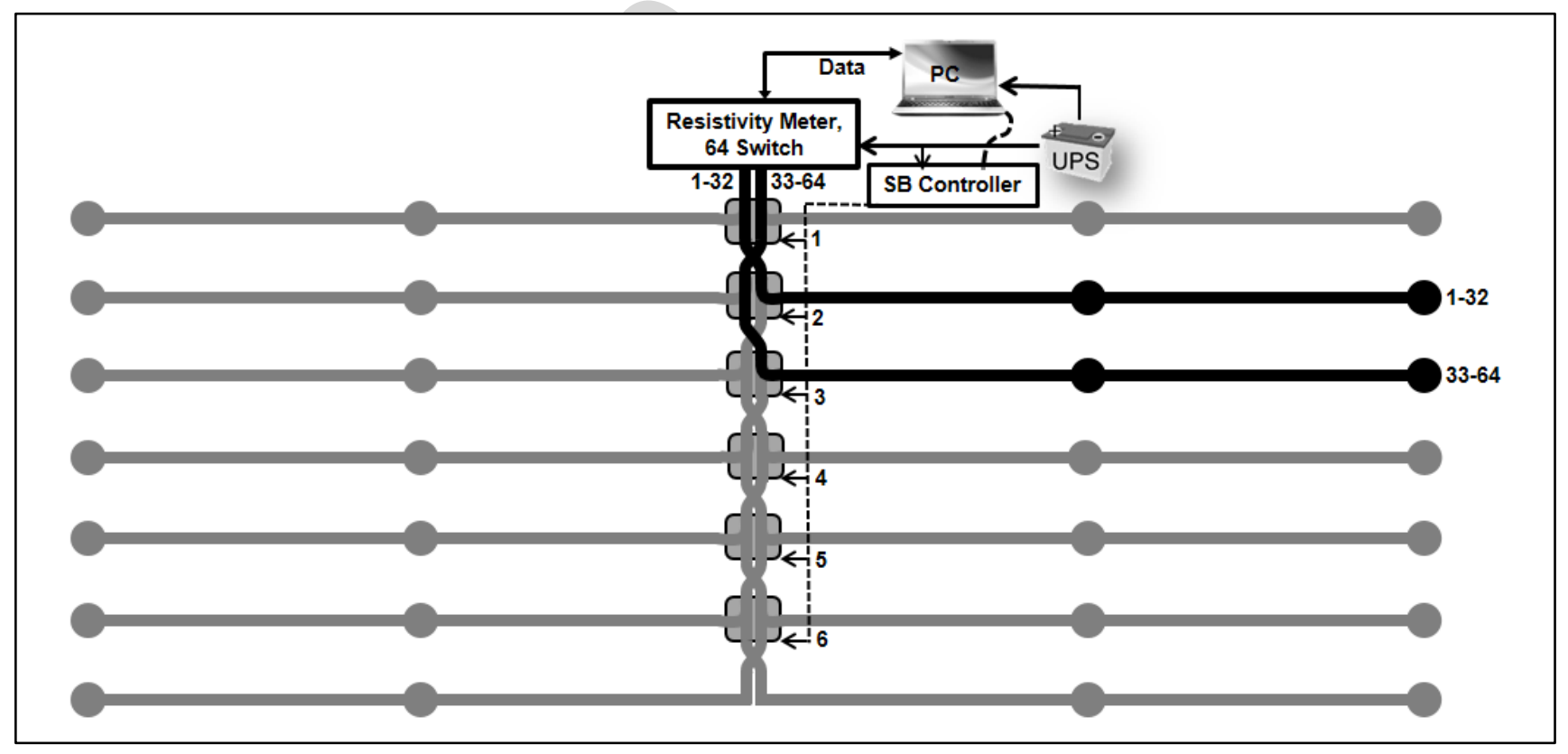


Figure 2 Schematic presentation of the extendable fishbone layout used for the 3D surveying. Each switchbox (shown as square boxes 1-6 in the middle) can either pass the instruction further down the fishbone or out to the line at the current switchbox. The black line indicates an instruction using one side of switchbox 2 and switchbox 3.

- Classic 2D sequences along any individual line. We collected measurements of gradient array types, with a total of 763 combinations per line.

- 3D data between cables on the same survey side. These configurations are of the type equatorial dipole-dipole. 110 combinations were collected per line-pair.

- 3-D data by activating cables on different lines and survey sides. These combinations are of the type cross-line gradients. 70 combinations were of this type per line pair.

After completion of each sequence data were automatically transferred from the resistivity meter to the PC for further processing and inversion. Figure 1 shows the location of the profiles used for 3D survey.

\section{Data Processing and Inversion}

The resistivity data were imported into Arhus Workbench (Auken et al., 2009) for processing. The processing mainly consisted of removing outliers resulting from poor electrode contact. The resistivity data were acquired using the maximum possible current in all cases, but when the electrode contact was poor the current levels were much lower (20-40 mA versus 400-500 mA). In turn, this resulted in 
poorer data quality and outliers resulting from this were easily detected and removed by plotting the data as pseudo sections.

\section{$2 \mathrm{D}$ inversion}

The data were inverted using the 2D inversion code AarhusInv (Auken et al., 2014a; Fiandaca et al., 2013). In the AarhusInv code it is also possible to compute the depth of investigation (DOI) an evolution of the DOI developed by (Christiansen and Auken, 2012). It is based on an approximated covariance analysis that uses both the actual model output from the inversion and the data standard deviations (Fiandaca et al., 2015)

\section{D inversion}

There are various inversion methods available for reconstructing the three dimensional resistivity structures from measured apparent resistivity data. Most of these inversion methods use the GaussNewton approach to minimize the misfit between data and model response (Park and Van, 1991). The first step in the inverse problem is to set up a suitable earth model for the forward problem, which is then solved either by the finite difference or the finite element method. The code by Gunter et al., (2006) is based on the triple grid inversion technique, which uses unstructured tetrahedral meshes and incorporates the topography in the problem.

\section{Water sampling, chemical analysis and ionic strength}

Groundwater samples were collected from the deep boreholes (Figure 1) by pumping up water through a polyethylene tube. Before sampling the $\mathrm{pH}, \mathrm{EC}$ and dissolved oxygen concentration were measured using a multi meter (WTW Multi 3420), and purging was conducted until the three 
parameters were stable. Water samples analysed for anions $\left(\mathrm{Cl}^{-}, \mathrm{NO}_{3}{ }^{-}, \mathrm{S}^{2-}\right.$ and $\left.\mathrm{SO}_{4}{ }^{2-}\right)$ were filtered through a $0.45 \mu \mathrm{m}$ filter into $6 \mathrm{~mL}$ plastic vials and immediately frozen until analysis. Samples analysed for cations $\left(\mathrm{Na}^{+}, \mathrm{K}^{+}, \mathrm{NH}_{4}{ }^{+}, \mathrm{Ca}^{2+}, \mathrm{Mn}^{2+}\right.$ and dissolved Fe) were filtered through a $0.20 \mu \mathrm{m}$ filter into 20 $\mathrm{mL}$ plastic vials and conserved with $1 \% \mathrm{v} / \mathrm{v}$ nitric acid. The samples were immediately transferred to a cooling box and stored at $10^{\circ} \mathrm{C}$ until analysis.

The analysis of anions was conducted by ion chromatography (Dionex ICS-1500 with an Ion Pac AS 14 A mm Column (P/N 056904) and Ion Pac AG14 Guard Column combined with an anion suppressor, Metrohm 833 IC), while cations were analysed using linductively Coupled Plasma Optical Emission Spectrometry (ICP-OES MPX Vista Axial, Auto sampler SPS3).The ionic strength was calculated based on the water samples collected in this study as well as chemical data from previous studies (Ludvigsen et al., 1998) conducted at Grindsted landfill using (Appelo and Postma, 2004): $\mu=$ $\frac{1}{2} \sum c_{i} z_{i}^{2}$, where $c$ and $z$ are the molar concentration and the electrical charge of a particular ion, respectively, and $i$ is the index denoting the $i^{\text {th }}$ ion. The following ions were included in the calculation: $\mathrm{HCO}_{3}^{-}, \mathrm{Cl}^{-}, \mathrm{NO}_{3}^{-}-\mathrm{N}, \mathrm{S}^{2-}, \mathrm{SO}_{4}{ }^{2-}, \mathrm{Na}^{+}, \mathrm{K}^{+}, \mathrm{NH}_{4}^{+}-\mathrm{N}, \mathrm{Ca}^{2+}, \mathrm{Mn}^{2+}$ and $\mathrm{Fe}^{2+}$. In samples lacking $\mathrm{HCO}_{3}^{-}$ measurements, the molar concentration was estimated by balancing the total electrical charge.

\section{Results and Discussions}

\section{D Resistivity models and ionic strength}

In Figure $3 \mathrm{EC}$ and ionic strength measurements from screens are compared. The EC and the ionic strength of the water samples compare very well, as expected, hence increased EC response reflects increased concentrations of major ions such as $\mathrm{HCO}_{3}{ }^{-}, \mathrm{Cl}^{-}, \mathrm{SO}_{4}{ }^{2-}, \mathrm{Na}^{+}, \mathrm{Ca}^{2+}$, and $\mathrm{Fe}^{2+}$. 


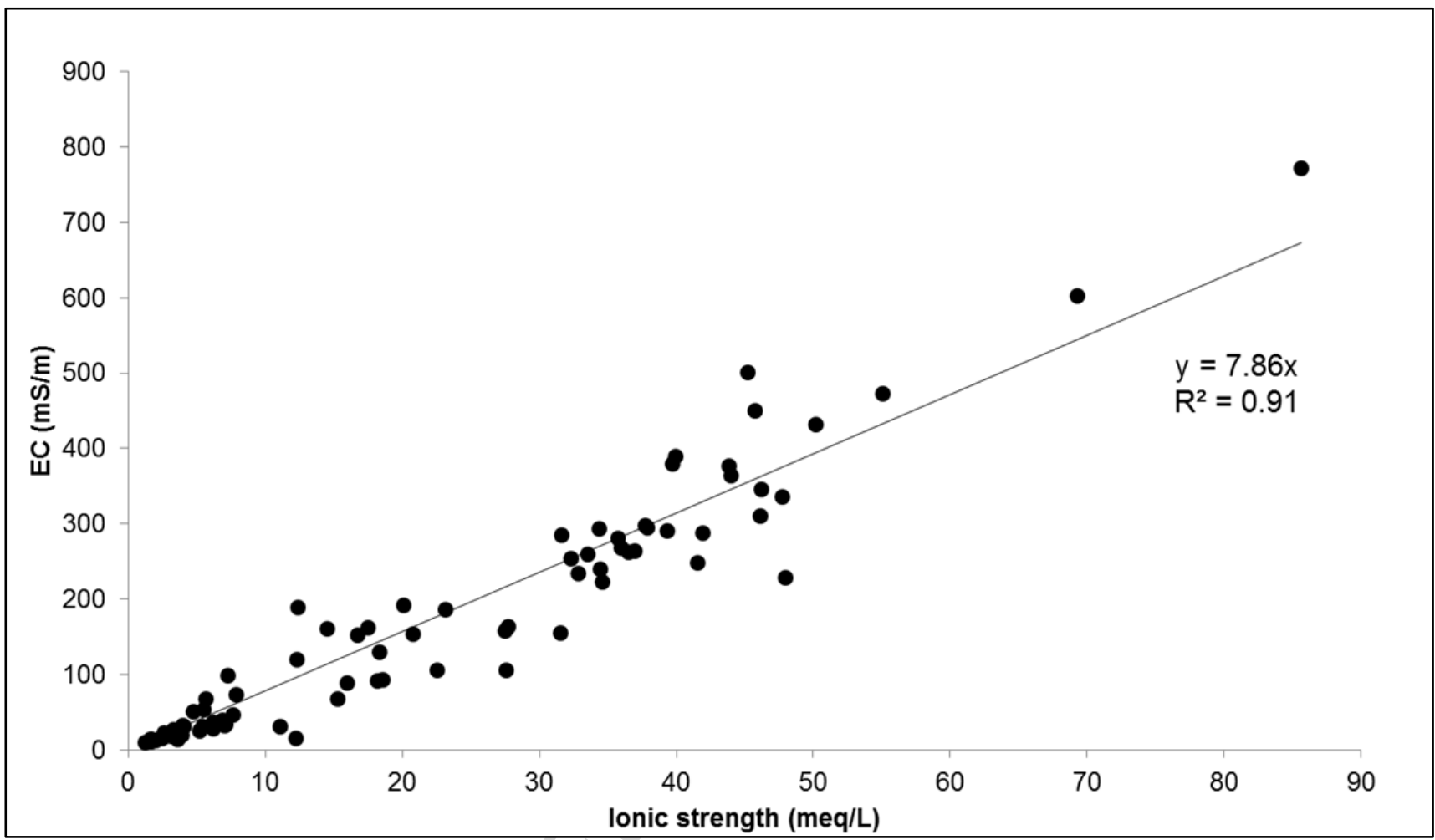

Figure 3: EC versus ionic strength (black points) based on chemical data collected in this study as well by Ludvigsen et al. (1998) and Kjeldsen et al. (1998a). The black line shows the linear regression model.

In the following we will compare the ionic strength of water samples with the resistivity responses in the landfill source and in the landfill leachate plume (Table 1, Figure 1, 4, and 5).

Figure 4 shows the 2D inversion results from Profile 1 which crosses the landfill and continues in the direction of groundwater flow. The resistivity model clearly shows the presence of a low-resistivity layer around $10 \mathrm{ohm}-\mathrm{m}$ at a depth of $12-15 \mathrm{~m}$ and approximately $20 \mathrm{~m}$ thick. This layer delineates the leachate plume, which originates from the landfill and migrates in the flow direction. The electrical conductivity gradually decreases in the flow direction. We expect that this anomaly is linked primarily to the increased ion-content in the leachate from the landfill. The resistivity model clearly shows that 
the plume moves towards the north-west and dives significantly. This dive might be partly due to density effects (Christensen et al., 2001). The depth and extend of the plume are confirmed by the ionic strength in bore hole 114.2122 (see Figure 1 for the borehole location), where the most contaminated screen is the uppermost one. In 114.2122 the highest ionic strength is $12-15$ below surface exactly where the lowest resistivity is indicated on Figure 4.

Figure 5 shows the panel of 2D inverted resistivity model combined from profiles 2 and 3 . The profiles

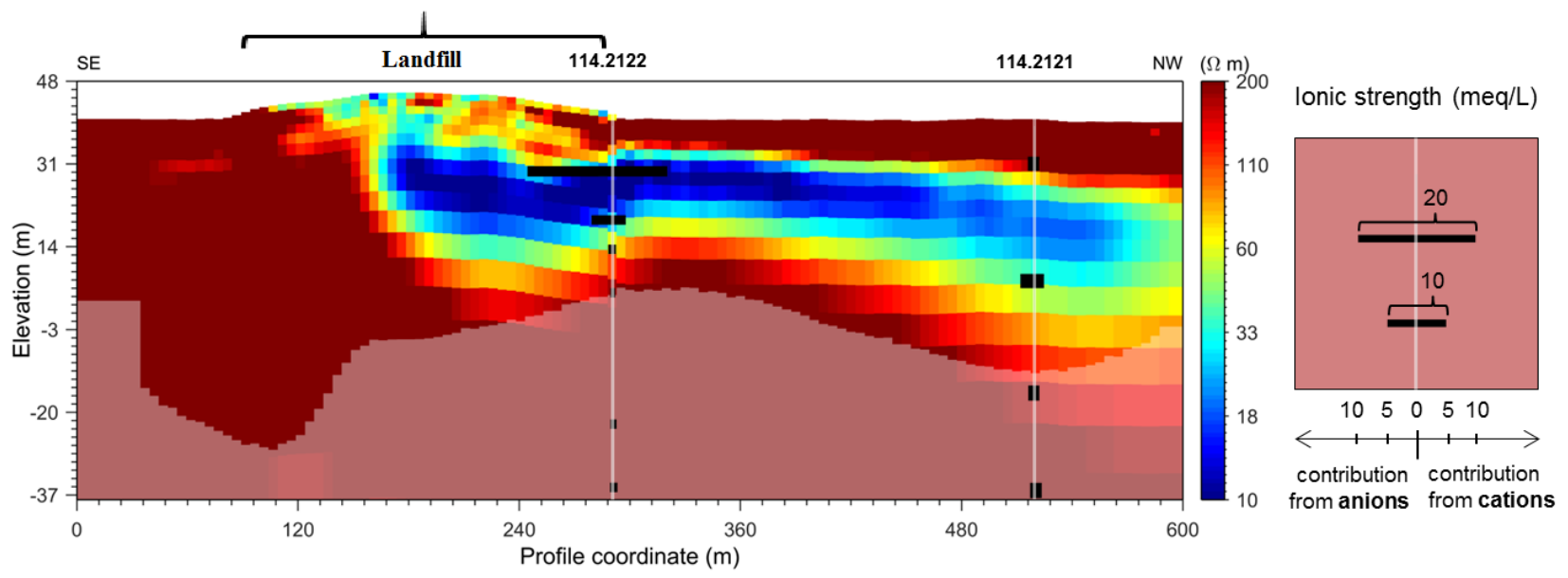

Figure 4. 2D inverted resistivity model along the profile crossing to the landfill and approximately in the direction of groundwater flow (Profile 1, see Figure 1). The shading at depth shows the estimated depth of investigation (DOI). Black bars show the ionic strength as detailed in the insert to the right.

intersect at borehole 114.2121 (Figure 1). The resistivity section clearly shows the extension of the plume across the flow direction. In the south-western end of the section (at coordinate $80 \mathrm{~m}$ ) the boundary of the leachate plume is found where the conductive layer disappears. The resistivity panel is compared to the ionic strength calculated at different depths from the seven boreholes along the 
section (Figure 1). The low resistive anomaly shows an excellent agreement with the ionic strength.

Overall it can be concluded that the ionic strength of the leachate plume is mapped well by the surface resistivity measurements.

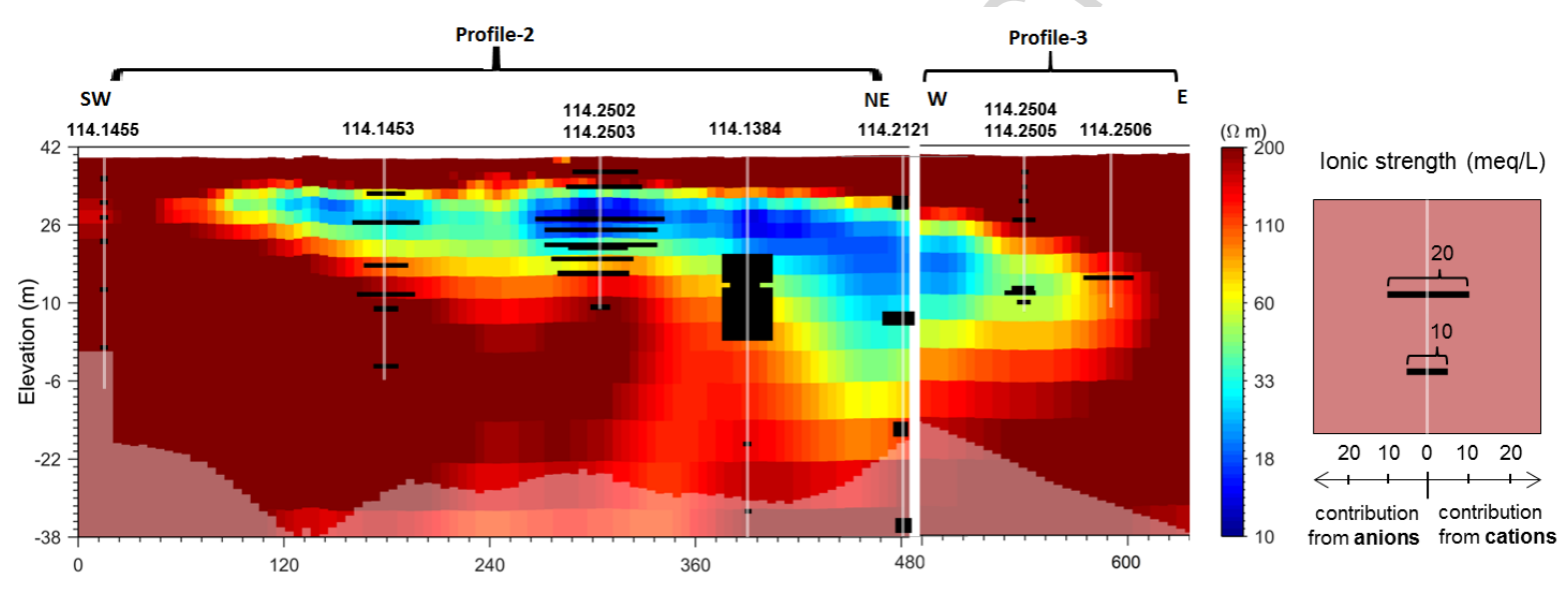

Figure 5 Combined inverted resistivity model (2D) of profile 2 and 3 (placement shown in Figure 1) approximately perpendicular to the overall flow direction in Figure 1. Ionic strengths are shown for the 7 boreholes close to the profile.

3D inversion results

Figure 6 shows the 3D DC inversion results as horizontal resistivity maps at different depths. In all these maps the leachate plume can be easily identified as low resistivity anomaly which is less than 10 ohm-m close to landfill and 10-30 ohm-m when moving away from the landfill. As we can see from the first horizontal resistivity map (a) which is at $15 \mathrm{~m}$ depth, the plume is centered closer the landfill and the lowest resistivity anomaly is seen here which corresponds to the higher ionic strength in the formation water. In the next two successively deeper resistivity maps at 25 and $35 \mathrm{~m}$ depth it is clear 
that plume seems to sink and migrate away from the landfill which was also observed in the 2D results of profile 1 (Figure 4).

Figure 7 shows the 3D cube of resistivities sliced vertically along a line approximately perpendicular to the groundwater flow direction and horizontally at a depth of $25 \mathrm{~m}$. The boundary of the landfill is marked by the black dotted line on the surface and the approximate groundwater flow direction (NW) is indicated as well.

The upper Quaternary sand layer is characterized by a fairly resistive layer (>500 ohm) and the low resistivity anomaly is a leachate plume in an otherwise relatively homogenous background geology. Just below the hotspot area (the location where the pharmaceutical chemical waste has been deposited, see Figure 1 and Table 1) resistivities are as low as $10 \mathrm{ohm}-\mathrm{m}$. The plume from this location is migrating in the direction of the groundwater flow.
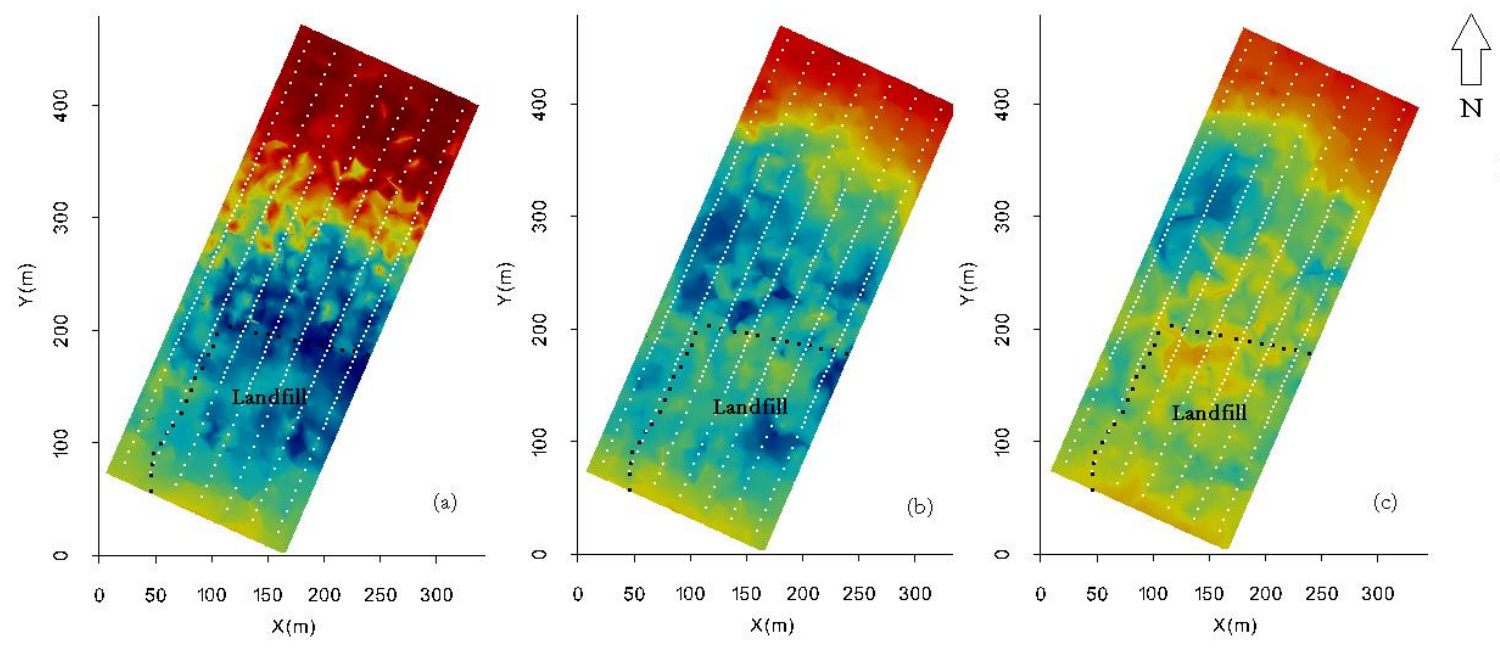

Resisitivity(ohm-m)

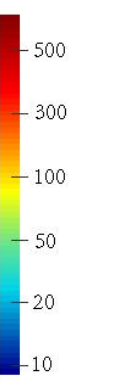

Figure $63 D$ DC inversion result shown as horizontal resistivity map at different elevation. (a)-30m, (b)-20m, (c)-10m, Boundary of the landfill is shown by black dotted line and position of the electrodes is shown as white dots. 
As different types of waste material were deposited in different parts of the landfill, different subplumes are migrating from the landfill (Kjeldsen et al., 1998a; Kjeldsen et al., 1998b). The different sources are reflected in 2 distinct plumes (Figure 7) originating from the hot spot with liquid industrial waste in the northern part of the source and from the area with mainly household waste (as well as demolition waste and smaller amounts of chemical waste) in the north-western part of the source, respectively. This is supported by the identification of two separate low resistivity anomalies shown by the red arrows and separated by a dashed yellow line in Figure 7.

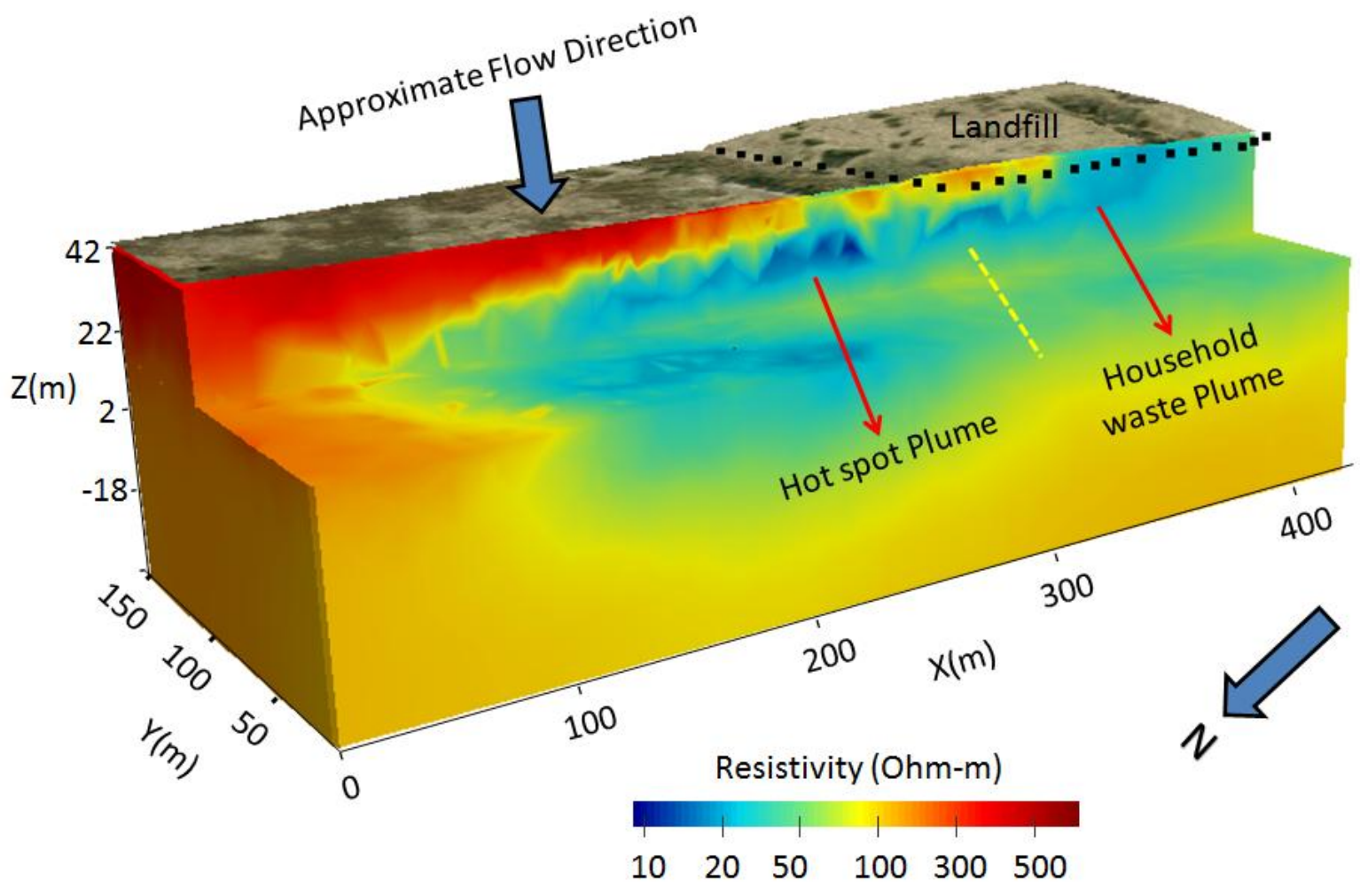

Figure 7 3D DC inversion result from the Grindsted landfill. The 3D cube of resistivities is sliced vertically along a line approximately perpendicular to the groundwater flow direction and horizontally at $25 \mathrm{~m}$ elevation. The boundary of the landfill is marked by the black dotted line on the surface and the approximate groundwater flow direction (NW) is shown by the blue arrow. 


\section{Final remarks}

In this study a 3D setup of $400 \mathrm{~m}$ by $150 \mathrm{~m}$ was used to delineate a leachate plume. Though, because the system is flexible and expandable any size of the setup can be chosen by scaling the dimensions of the cables. With the exact same setup we have carried out detailed studies of the geological structures around a meander-bow in a river bed with a layout size of only 126 by $42 \mathrm{~m}$ (Maurya et al., 2016). The number of cables and electrodes were identical to the layout presented here. Likewise, the setup can be expanded by using longer cables and/or more switchboxes in the fishbone structure.

In this study only the DC part of the data were used, but actually induced polarization (IP) data were collected as well, without any alterations to the setup described here. These data might contain valuable information about surface processes initiated by the leachate at the landfill or in the vicinity of the fill, which is the aim of current research. Likewise the IP data will help to separate the geological signals from the contaminant signals by the effect of clay content on the IP signals (Gazoty et al., 2012).

\section{Conclusion}

We have used surface based resistivity tomography (both 2D and 3D) to map the leachate plume from an old landfill site without liner or leachate collection. An expandable 3D ERT system was used for the 3D data collection and the results have been modelled using the full 3D inversion modeling package (BERT). The model was visualized as horizontal resistivity maps at different depth and the combination of vertical and horizontal sections. Three 2D profiles were acquired, one along the 
groundwater flow direction and other two perpendicular the groundwater flow direction. 2D resistivity models were compared against the EC and ionic strength calculated from water chemistry in samples from borehole at different depth.

The 3D inverted resistivity models were able to delineate the spatial distribution of the leachate plume. The horizontal resistivity maps show two distinct low resistivity anomalies due to different type of waste material deposited at the landfill. In particular a diving plume arising from an area liquid industrial waste was delineated very well.

2D sections were used to create resistivity models along transects parallel and perpendicular to the groundwater flow direction, while at the same time crossing boreholes in the area with screens for water chemistry. As shown by the comparison of resistivity and ionic strength calculated from chemical analysis, the presence of higher concentration of inorganic constituents in the groundwater is clearly seen as low resistivity anomaly in the resistivity models. A resistivity profile perpendicular to the overall flow direction has been compared with ionic strength of the contaminated groundwater. The pattern and distribution of conductive anomaly seen in resistivity model compares fairly well with the profile of ionic strength.

Overall ERT results shows that method has been successful in delineating the landfill leachate plume and a good correlation was found between the resistivity models and lonic strength.

\section{Acknowledgements}

Support was provided by the research project GEOCON, Advancing Geological, geophysical and Contaminant monitoring technologies for contaminated site investigation (contract 1305-00004B). 
The funding for GEOCON is provided by The Danish Council for Strategic Research under the

Programme commission on sustainable energy and environment

\section{References}

Acworth, R.I., Jorstad, L.B., 2006. Integration of multi-channel piezometry and electrical tomography to better define chemical heterogeneity in a landfill leachate plume within a sand aquifer. Journal of Contaminant Hydrology 83, 200-220.

Albrechtsen, H.J., Bjerg, P.L., Ludvigsen, L., Rugge, K., Christensen, T.H., 1999. An anaerobic field injection experiment in a landfill leachate plume, Grindsted, Denmark 2. Deduction of anaerobic (methanogenic, sulfate-, and Fe(III)-reducing) redox conditions. Water Resources Research 35, 1247 1256.

Appelo, C.A.J., Postma, D., 2004. Geochemistry, Groundwater and Pollution, Second Edition. CRC Press.

Auken, E., Christiansen, A.V., Kirkegaard, C., Fiandaca, G., Schamper, C., Behroozmand, A.A., Binley, A., Nielsen, E., Effers $\varnothing$, F., Christensen, N.B., Sørensen, K.I., Foged, N., Vignoli, G., 2014a. An overview of a highly versatile forward and stable inverse algorithm for airborne, ground-based and borehole electromagnetic and electric data. Explor. Geophys, 1-13.

Auken, E., Doetsch, J., Fiandaca, G., Christiansen, A.V., Gazoty, A., Cahill, A.G., Jakobsen, R., 2014b. Imaging subsurface migration of dissolved $\mathrm{CO} 2$ in a shallow aquifer using 3-D time-lapse electrical resistivity tomography. Journal of Applied Geophysics, 31-41.

Auken, E., Viezzoli, A., Christiansen, A.V., 2009. A Single Software For Processing, Inversion, And Presentation Of Aem Data Of Different Systems: The Aarhus Workbench. ASEG, Adelaide.

Barker, J.F., Tessmann, J.S., Plotz, P.E., Reinhard, M., 1986. The organic geochemistry of a sanitary landfill leachate plume. Journal of Contaminant Hydrology 1, 171-189.

Barlebo, H.C., Hill, M.C., Rosbjerg, D., Jensen, K.H., 1998. Concentration data and dimensionality in groundwater models: Evaluation using inverse modelling. Nordic Hydrology 29, 149-178.

Baxter, K.M., 1985. The effects of a hazardous and a domestic waste landfill on the trace organicquality of chalk groundwater at a site in east-Anglia. Science of the Total Environment 47, 93-98.

Bernstone, C., Dahlin, T., Ohlsson, T., Hogland, H., 2000. DC-resistivity mapping of internal landfill structures: two pre-excavation surveys. Environmental Geology 39, 360-371. 
Bjerg, P.L., Albrechtsen, H.J., Kjeldsen, P., Christensen, T.H., Cozzarelli, I.M., 2014. 11.16 - The Biogeochemistry of Contaminant Groundwater Plumes Arising from Waste Disposal Facilities A2 Holland, Heinrich D, in: Turekian, K.K. (Ed.), Treatise on Geochemistry (Second Edition). Elsevier, Oxford, pp. 573-605.

Bjerg, P.L., Rugge, K., Cortsen, J., Nielsen, P.H., Christensen, T.H., 1999. Degradation of aromatic and chlorinated aliphatic hydrocarbons in the anaerobic part of the Grindsted Landfill leachate plume: In situ microcosm and laboratory batch experiments. Ground Water 37, 113-121.

Bjerg, P.L., Rugge, K., Pedersen, J.K., Christensen, T.H., 1995. Distribution of redox-sensitive groundwater quality parameters downgradient of a landfill(Grindsted, Denmark). Environmental Science \&amp; Technology 29, 1387-1394.

Casado, I., Mahjoub, H., Lovera, R., Fernandez, J., Casas, A., 2015. Use of electrical tomography methods to determinate the extension and main migration routes of uncontrolled landfill leachates in fractured areas. Science of the Total Environment 506, 546-553.

Christensen, T.H., Kjeldsen, P., Bjerg, P.L., Jensen, D.L., Christensen, J.B., Baun, A., Albrechtsen, H.J., Heron, C., 2001. Biogeochemistry of landfill leachate plumes. Applied Geochemistry 16, 659-718.

Christiansen, A.V., Auken, E., 2012. A global measure for depth of investigation. Geophysics 77, WB171-WB177.

Cozzarelli, I.M., Boehlke, J.K., Masoner, J., Breit, G.N., Lorah, M.M., Tuttle, M.L.W., Jaeschke, J.B., 2011. Biogeochemical Evolution of a Landfill Leachate Plume, Norman, Oklahoma. Ground Water 49, 663-687.

Dahlin, T., Bernstone, C., Loke, M.H., 2002. A 3-D resistivity investigation of a contaminated site at Lernacken, Sweden. Geophysics 67, 1692-1700.

Dahlin, T., Zhou, B., 2006. Multiple-gradient array measurements for multichannel 2D resistivity imaging. Near Surface Geophysics 4, 113-123.

Fiandaca, G., Christiansen, A.V., Auken, E., 2015. Depth of investigation for multi-parameters inversions, 21st European Meeting of Environmental and Engineering Geophysics, Turin, Italy.

Fiandaca, G., Ramm, J., Binley, A., Gazoty, A., Christiansen, A.V., Auken, E., 2013. Resolving spectral information from time domain induced polarization data through 2-D inversion. Geophysical Journal International 192, 631-646.

Gazoty, A., Fiandaca, G., Pedersen, J., Auken, E., Christiansen, A.V., 2012. Mapping of landfills using time-domain spectral induced polarization data: The Eskelund case study. Near Surface Geophysics $10,575-586$. 
Günther, T., Rücker, C., Spitzer, K., 2006. Three-dimensional modelling and inversion of dc resistivity data incorporating topography - II. Inversion. Geophysical Journal International 166, 506-517.

Heron, G., Bjerg, P.L., Gravesen, P., Ludvigsen, L., Christensen, T.H., 1998. Geology and sediment geochemistry of a landfill leachate contaminated aquifer (Grindsted, Denmark). Journal of Contaminant Hydrology 29, 301-317.

Kjeldsen, P., Bjerg, P.L., Rugge, K., Christensen, T.H., Pedersen, J.K., 1998a. Characterization of an old municipal landfill (Grindsted, Denmark) as a groundwater pollution source: landfill hydrology and leachate migration. Waste Management \& Research 16, 14-22.

Kjeldsen, P., Grundtvig, A., Winther, P., Andersen, J.S., 1998b. Characterization of an old municipal landfill (Grindsted, Denmark) as a groundwater pollution source: landfill history and leachate composition. Waste Management \& Research 16, 3-13.

Konstantaki, L.A., Ghose, R., Draganov, D., Diaferia, G., Heimovaara, T., 2015. Characterization of a heterogeneous landfill using seismic and electrical resistivity data. Geophysics 80, EN13-EN25.

Loke, M.H., Barker, R.D., 1996a. Practical techniques for 3D resistivity surveys and data inversion. Geophysical Prospecting 44, 499-523.

Loke, M.H., Barker, R.D., 1996b. Rapid least squares inversion of apparent resistivity pseudosections by a quasi-Newton method. Geophysical Prospecting 44, 131-152.

Lonborg, M.J., Engesgaard, P., Bjerg, P.L., Rosbjerg, D., 2006. A steady state redox zone approach for modeling the transport and degradation of xenobiotic organic compounds from a landfill site. Journal of Contaminant Hydrology 87, 191-210.

Ludvigsen, L., Albrechtsen, H.J., Heron, G., Bjerg, P.L., Christensen, T.H., 1998. Anaerobic microbial redox processes in a landfill leachate contaminated aquifer (Grindsted, Denmark). Journal of Contaminant Hydrology 33, 273-291.

Maurya, P.K., Christiansen, A.V., Fiandaca, G., Auken, E., 2016. 3D Resistivity and Induced Polarization for Leachate Plume Identification at a Challenging Field Site, 22nd European Meeting of Environmental and Engineering Geophysics, Barcelona,Spain.

Ogilvy, R., Meldrum, P., Chambers, J., Williams, G., 2002. The Use of 3D Electrical Resistivity Tomography to Characterise Waste and Leachate Distribution within a Closed Landfill, Thriplow, UK. Journal of Environmental and Engineering Geophysics 7, 11-18.

Orbicon, 2013. 3 dybe boringer ved Grindsted (Data report in Danish), Region Syddanmark, https://www.rsyd.dk/dwn358934. 
Park, S.K., Van, G.P., 1991. Inversion of pole-pole data for 3-d resistivity structure beneath arrays of electrodes. Geophysics 56, 951-960.

Perozzi, L., Holliger, K., 2008. Detection and Characterization of Preferential Flow Paths in the Downstream Area of a Hazardous Landfill. Journal of Environmental and Engineering Geophysics 13, 343-350.

Rugge, K., Bjerg, P.L., Pedersen, J.K., Mosbaek, H., Christensen, T.H., 1999. An anaerobic field injection experiment in a landfill leachate plume, Grindsted, Denmark 1. Experimental setup, tracer movement, and fate of aromatic and chlorinated compounds. Water Resources Research 35, 1231-1246.

Sasaki, Y., 1994. 3-D resistivity inversion using the finite-element method. Geophysics 59, 1839-1848.

Slater, L., Binley, A., 2006. Engineered barriers for pollutant containment and remediation. Applied Hydrogeophysics 71, 293-317.

Vargemezis, G., Tsourlos, P., Giannopoulos, A., Trilyrakis, P., 2015. 3D electrical resistivity tomography technique for the investigation of a construction and demolition waste landfill site. Studia Geophysica Et Geodaetica 59, 461-476.

Wang, T.P., Chen, C.C., Tong, L.T., Chang, P.Y., Chen, Y.C., Dong, T.H., Liu, H.C., Lin, C.P., Yang, K.H., Ho, C.J., Cheng, S.N., 2015. Applying FDEM, ERT and GPR at a site with soil contamination: A case study. Journal of Applied Geophysics 121, 21-30.

Yi, M.J., Kim, J.H., Song, Y., Cho, S.J., Chung, S.H., Suh, J.H., 2001. Three-dimensional imaging of subsurface structures using resistivity data. Geophysical Prospecting 49, 483-497.

Zhang, J., Mackie, R.L., Madden, T.R., 1995. 3-D resistivity forward modeling and inversion using conjugate gradients. Geophysics 60, 1313-1325.

Zume, J.T., Tarhule, A., Christenson, S., 2006. Subsurface Imaging of an Abandoned Solid Waste Landfill Site in Norman, Oklahoma. Ground Water Monitoring \& Remediation 26, 62-69. 
Research Highlights

- ERT method was used for mapping the landfill leachate plume

- Combined use of 2D and large scale 3D data sets.

- Inverted resistivity model were compared with lonic strength of the leachate plume 